\title{
Do Império à cidade multiétnica: austríacos no sul do Brasil $^{\star}$
}

\author{
Regina Weber ${ }^{\star *}$
}

Este artigo enfoca as circunstâncias que configuraram uma identidade específica a imigrantes identificados como "austríacos". O lócus principal da pesquisa é um núcleo de povoamento no interior do Rio Grande do Sul, reunindo dados que vão do final do século XIX ao final do século XX, período que contempla, em termos internacionais, a existência, ainda que a poucas décadas do seu final, do Império Austro-Húngaro e, em nível local, investimentos recentes no memorialismo étnico. Está sendo dado destaque aos agentes que realizam conexões entre mundos e tempos diferentes e aos modos pelos quais são operacionalizadas as representações do passado.

Palavras-chave: Imigração austríaca. Império Austro-Húngaro. Multiétnico. Memória. Representações.

\footnotetext{
*Este artigo incorporou contribuições recebidas no simpósio “Imigrantes do Império Austro-Húngaro nas Américas: uma agenda de pesquisa", durante o XVII Congreso Internacional de AHILA (Asociación de Historiadores Latinoamericanistas Europeos), em Berlim, 2014.

** Universidade Federal do Rio Grande do Sul (UFRGS), Porto Alegre-RS, Brasil (regina.weber@ufrgs.br; https://orcid. org/0000-0002-6795-0815).
} 


\section{Introdução}

Em contextos de migrações internacionais, é sabido que as identidades, mesmo quando as comunidades permanecem relativamente coesas na nova sociedade, sofrem alterações que são determinadas pelas relações que se estabelecem entre os habitantes antigos e os adventícios, assim como pelas oportunidades de ocupação de espaços territoriais, profissionais e sociais encontradas pelos imigrantes. As identidades sociais, assim, sofrem reelaborações ao longo do tempo, permanecendo o passado como uma memória passível de reconfigurações sucessivas. Outros dois pressupostos acompanham as análises deste artigo. 0 primeiro presume que a persistência ou a redescoberta de identidades ancoradas em processos históricos que, originalmente, ocorreram há mais de um século deve-se à ação que se efetiva ou se atualiza no presente. 0 segundo pressuposto é que, mesmo em casos de imigrantes majoritariamente camponeses ou que se instalaram em áreas rurais, a mobilização étnica que tem efeito efetivo sobre a sociedade envolvente deve-se a agentes (WEBER, 2014) que, via de regra, são descendentes dos primitivos imigrantes e possuem inserção urbana e no meio "letrado", ou que emigraram em fases posteriores às levas do final do século XIX, vinculando-se a redes de relações já abertas pelos seus predecessores.

Um exemplo de transformações identitárias em contexto interétnico pode ser observado em uma "categoria”, no sentido de "atribuição categórica” de Barth (2000), ou “classificação", no sentido atribuído por Bourdieu (1989), que se manifestou - e eventualmente ainda se manifesta - no sul do Brasil, distinguindo os “brasileiros" dos “de origem”. Um primeiro registro acadêmico deste fenômeno foi feito por Giralda Seyferth (1982), para a região do Vale do Itajaí; posteriormente, outros pesquisadores descreveram situações semelhantes (WEBER, 2002, p. 184; FERREIRA, 2006). Ser “de origem" significava ser descendente de imigrantes europeus que chegaram ao Brasil no final do século XIX e foram direcionados para áreas rurais; o termo "brasileiro", em contraposição, designava o habitante de ascendência luso-brasileira, numa acepção diferente, portanto, de seu homônimo que designa a nacionalidade. No caso do Rio Grande do Sul, o processo que reduz a complexidade das identidades dos adventícios, ocasionando um esquema classificatório mais amplo (SARNA, 1978, p. 372), resultou, com relação aos imigrantes europeus da segunda metade do século XIX, no reconhecimento de três grandes grupos: alemães, italianos e poloneses. Neste artigo, os termos que designam grupos imigrantes, aplicados igualmente a descendentes, referem-se a identidades de “origem”, as quais se distanciam, com algumas exceções, do vínculo nacionalista com a nação de emigração. ${ }^{1}$

\footnotetext{
${ }^{1}$ A vinculação entre "identidade de origem" e identidade étnica está embasada em Weber (1994, p. 270): “nem toda crença na afinidade de origem baseia-se na igualdade dos costumes e do hábito. Mas, apesar de grandes divergências neste campo, semelhante crença pode existir e desenvolver uma força criadora de comunidade, quando apoiada na lembrança de uma migração real; de uma colonização ou emigração individual”.
} 
A contabilidade de estrangeiros pelos censos populacionais e registros numéricos similares não são, como se sabe, um espelho de grupos étnicos formados por processo migratório, pois encobrem os descendentes nascidos no país, ignoram povos que portam passaporte de nações invasoras e podem não distinguir entre residentes e temporários, como o caso de uruguaios e argentinos, populações com grande mobilidade pela fronteira sul do país. Porém, estes números indicam a probabilidade de formação de comunidades étnicas. A noção de "Colônia", recorrente neste artigo, acompanha o sentido exposto por Lima Jr. (1996, p. 55), para quem existe colônia com "C" maiúsculo, que corresponde às antigas áreas de terras das companhias públicas ou privadas que as parcelaram para receber colonos, e colônia com "c" minúsculo, que é uma destas parcelas ocupada por um "colono". As subdivisões das Colônias para alocar várias unidades familiares foram denominadas "Linhas".

A Tabela 1 apresenta uma visão da recepção de imigrantes no estado do Rio Grande do Sul no final do século XIX, entre os quais os austríacos são um grupo minoritário. Os mais de cem grupos familiares de austríacos registrados nas fontes oficiais não se dirigiram a ljuhy Grande, termo que originalmente designava o núcleo de assentamento que é o foco deste artigo. Já a Tabela 2, compilada a partir de fontes diversas, registra a efetiva chegada de austríacos a ljuí, com destaque para o ano de 1893, que se tornaria emblemático para a memória dos imigrantes. Entre as duas tabelas há uma discrepância com relação a seis famílias austríacas que chegaram a ljuí em 1892 e não constam nas fontes que alimentaram a Tabela 1. Provavelmente trata-se de um caso de reassentamento interno, frequente naqueles anos. A Tabela 2 também informa a pequena proporção de unidades familiares formadas por um único indivíduo, quase sempre homens. A concentração de núcleos familiares tende a favorecer a memória da emigração e os casamentos intraétnicos.

TABELA 1

Imigrantes entrados na província do Rio Grande do Sul em 1891 e 1892, segundo nacionalidade. Contagem por indivíduos que encabeçam as famílias ou emigram sozinhos

\begin{tabular}{lccc}
\hline \multicolumn{1}{c}{ Nacionalidade } & $\begin{array}{c}\text { Número de cabeças de } \\
\text { família }\end{array}$ & $\begin{array}{c}\text { Porcentagem por } \\
\text { nacionalidade no RGS }\end{array}$ & $\begin{array}{c}\text { Número de cabeças de } \\
\text { família com destino a ljuí }\end{array}$ \\
\hline Italiana & 2.019 & 62,50 & 1 \\
Alemã & 420 & 13,00 & 35 \\
Espanhola & 211 & 6,50 & 2 \\
Polonesa & 154 & 4,76 & 2 \\
Sueca & 147 & 4,55 & 96 \\
Austríaca & 101 & 3,12 & 0 \\
Francesa & 50 & 1,54 & 1 \\
Portugal & 48 & 1,48 & 0 \\
Outros & 80 & 2,47 & 2 \\
Total & $\mathbf{3 . 2 3 0}$ & & $\mathbf{1 3 9}$ \\
\hline
\end{tabular}

Fonte: Gênesis (1993). 
TABELA 2

Imigrantes austríacos que chegaram a ljuí entre 1892 e 1893

\begin{tabular}{lccc}
\hline \multicolumn{1}{c}{ Data da chegada } & Famílias & Total de indivíduos & $\begin{array}{c}\text { Indivíduos que } \\
\text { emigram sozinhos }\end{array}$ \\
\hline 1892 & 6 & 19 & - \\
1893, 24 fev. & 49 & 177 & 3 \\
1893, abril e maio & 6 & 12 & 2 \\
Total 1892/1893 & $\mathbf{6 1}$ & $\mathbf{2 0 8}$ & $\mathbf{5}$ \\
\hline
\end{tabular}

Fonte: Austríacos (2013, p. 8). Elaboração da autora.

Outro registro populacional da Colônia ljuí é o relato de um missionário polonês escrito em 1898 e traduzido quase 80 anos depois, segundo o qual haveria 500 famílias de poloneses, 200 famílias de alemães, uma centena de famílias austríacas, uma centena de famílias italianas, 50 suecas, além de algumas dezenas de famílias de lituanos, rutenos e tchecos (CUBER, 1975, p. 30). Sendo um habitante da Europa oriental, Cuber sabia distinguir povos diferentes, reconhecimento nem sempre presente em dados oficiais. Cada um dos registros demográficos citados fotografa a evolução do povoamento local em um tempo diferente. Sabe-se, pelo próprio relato de Cuber (1975, p. 42), que a concentração dos poloneses diminuiu nos próximos anos com seu deslocamento para outras localidades, enquanto os dados oficiais registram o aumento do ingresso de alemães e italianos, seguidos pelos austríacos, conforme mostra a Tabela 3.

TABELA 3

Imigrantes enviados à colônia ljuí - 1900-1902

\begin{tabular}{cccccc}
\hline Italianos & Alemães & Austríacos & Espanhóis & Polacos & Outros (1) \\
\hline 191 & 175 & 50 & 30 & 25 & 7 \\
\hline
\end{tabular}

Fonte: Azevedo (2018, p. 19).

(1) Correspondem a três dinamarqueses, três holandeses e um sueco.

Além de fornecerem dados sobre imigrantes austríacos, as tabelas apresentadas anteriormente sinalizam o perfil multiétnico que a cidade foi adquirindo desde seus tempos de colônia. Este perfil, com variações de grupos étnicos, pode ser atribuído ao estado do Rio Grande do Sul em seu conjunto. Os números do Censo Demográfico de 1920 e 1940 (Tabela 4) corroboram a representação de alemães, italianos e poloneses como os principais conjuntos de imigrantes no Rio Grande do Sul e tornam plausível que imigrantes austríacos se aproximassem dos alemães, um grupo cinco vezes mais numeroso, mas com afinidades linguísticas e históricas. 0 Censo de 1940 mostra uma queda dos estrangeiros de modo geral e, em especial, dos austríacos. Contudo, se este dado representa o falecimento dos velhos imigrantes e o nascimento das novas gerações no país, ou a diminuição da chegada de novos imigrantes, ele não nos indica um esmorecimento da identidade. 
TABELA 4

Principais estrangeiros, segundo país de origem Rio Grande do Sul - 1920-1940

\begin{tabular}{|c|c|c|c|c|c|}
\hline & País de origem & $\begin{array}{c}\text { Recenseamento } \\
\text { de } 1920\end{array}$ & & País de origem & $\begin{array}{c}\text { Recenseamento } \\
\text { de } 1940\end{array}$ \\
\hline $1 \stackrel{0}{1}$ & Itália & 49.136 & $1 \stackrel{0}{0}$ & Itália & 24.603 \\
\hline $2^{0}$ & Uruguai & 31.570 & $2^{0}$ & Uruguai & 22.759 \\
\hline 30 & Alemanha & 19.652 & 30 & Alemanha & 18.120 \\
\hline 40 & Polônia & 10.451 & 40 & Polônia & 11.172 \\
\hline 5은 & URSS & 9.373 & $5^{\circ}$ & URSS & 8.055 \\
\hline $6^{0}$ & Portugal & 9.324 & $6^{0}$ & Portugal & 7.167 \\
\hline $7^{0}$ & Argentina & 5.998 & $7^{0}$ & Argentina & 5.224 \\
\hline $8^{0}$ & Espanha & 5.359 & $8^{0}$ & Espanha & 3.208 \\
\hline 9음 & Áustria & 4.193 & 90 & Síria & 2.108 \\
\hline $10^{\circ}$ & Turco-árabes & 2.565 & $10^{\circ}$ & Áustria & 206 \\
\hline
\end{tabular}

Fonte: Brasil (1926). IBGE. Recenseamento Geral do Brasil, Censo Demográfico 1940. Elaboração da autora.

Se os registros étnicos dos imigrantes estão sujeitos a muitas variáveis, como apontou Prutsch (2011, p. 10-11) para os austro-húngaros, o pesquisador que almeja estudar identidades específicas precisa observar e encontrar as endo-definições, aquelas que emanam dos próprios indivíduos ou grupos familiares.

A discussão aqui proposta também se ampara em debates sobre "assimilação", que conduziram Herbert Gans (1979) a propor a noção de "etnicidade simbólica”. A teoria da inevitabilidade da aculturação e da assimilação, que acarretaria a absorção dos grupos étnicos em uma mais ampla cultura, que já foi sociologicamente dominante nos Estados Unidos, recebeu várias críticas baseadas em observações que indicavam a persistência de culturas e organizações étnicas, a organização política étnica, o retorno do fenômeno na terceira geração e a emergência dos revivals étnicos. 0 argumento de Gans é de que a assimilação continua ocorrendo, e explica os "revivals étnicos" a partir da ideia de "etnicidade simbólica": estando menos vinculada a papéis, a etnicidade, agora calcada em símbolos étnicos tomados da antiga cultura étnica, torna-se uma atividade praticada em momentos de lazer, satisfazendo a "necessidade de identidade" dos indivíduos de um modo não conflitante com suas atividades cotidianas, decorrentes justamente do processo de assimilação.

\section{Império, nação, comunidade: do que se nutre a representação do passado?}

O Império do qual emigraram os "austríacos" era uma entidade composta - a Austro-Hungria -, formada em 1867 após a Áustria sofrer derrotas para a Prússia e se ver forçada a fazer concessões à Hungria. Esta composição continha o Império Austríaco, que se formou ao longo do século XVII, com a dinastia Habsburgo controlando territórios de populações camponesas servis compostas por tchecos, eslovacos, húngaros, alemães ou austríacos (ANDERSON, 1995, p. 300, 325). Wachowicz (1981, p. 33) argumenta que a 
amplitude do moribundo e heterogêneo Império Austro-Húngaro no século XIX contribuiu para aumentar o número de imigrantes que podiam se considerar e serem considerados pelos outros como "austríacos". Se não existiam a cidadania e nem o passaporte austro-húngaro, a categoria austro-húngaro, representando a Monarquia Dual, manifestava-se nas relações exteriores, como em consulados (PRUTSCH; BERTONHA; SZENTE-VARGA, 2017). Às voltas com esta complexidade de nacionalidades em seu estudo sobre os austríacos que se instalaram em ljuí, André Haiske (2017, p. 29) conclui que eles eram considerados e se consideravam "austríacos", o que está em sintonia com a descrição de Ursula Prutsch (2011, p. 4) para a imigração austríaca para o Brasil como um todo, entre 1876 e 1910: mais de $80 \%$ dos imigrantes provinham da metade austríaca do Império, ainda que nem todos falassem alemão (PRUTSCH, 2011, p. 10).

Na mais icônica imagem dos imigrantes austríacos que chegaram a ljuí a partir da última década do século XIX (Figura 1), a homenagem ao Império faz parte da afirmação da identidade austríaca. Chegados há pouco mais de uma década, instalados em uma região cujo acesso até hoje depende de estradas não pavimentadas, estes imigrantes dispunham-se a homenagear a autoridade máxima de um império ao qual eles ainda sentiam-se ligados. Uma década mais tarde, quando Franz Joseph, imperador da Áustria e rei da Hungria, Croácia e Boêmia, faleceu durante a I Guerra Mundial, várias comunidades locais enviaram ao representante do consulado do Império Austro-Húngaro em Porto Alegre uma carta de apoio com assinaturas (HAISKE, 2017, p. 38).

FIGURA 1

Reunião festiva no aniversário do imperador Francisco José da Áustria - 18 agosto 1907. Sociedade Escolar dos Imigrantes Austríacos, na Linha 6 leste, de ljui

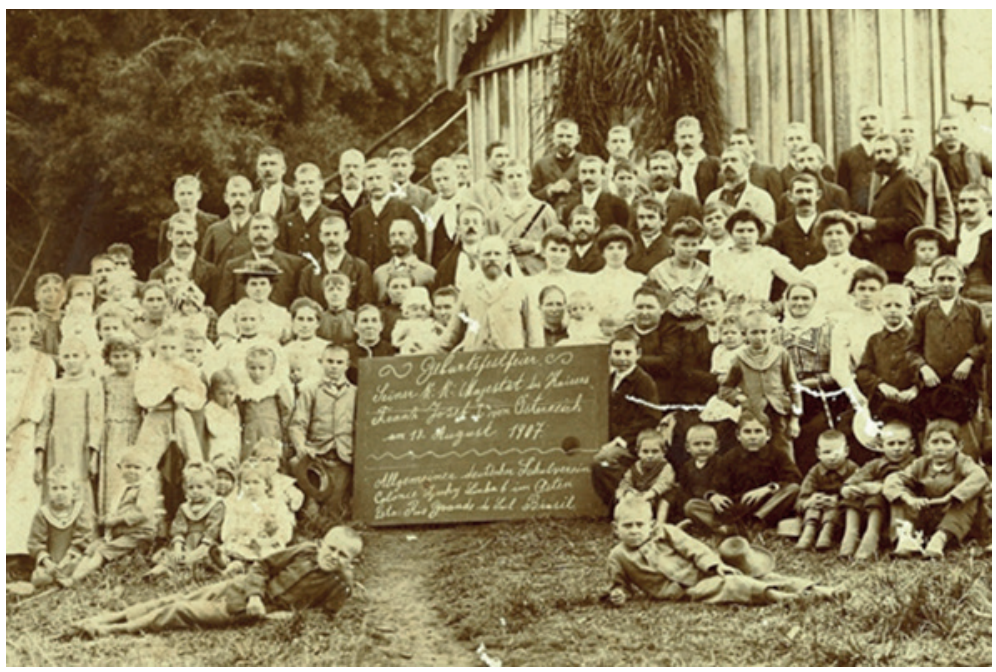

Fonte: Museu Antropológico Diretor Pestana. FIDENE. AFT-AI-CB.4.1 490. 
O Império Austro-Húngaro foi deixando de ser um elemento de "realce"2 na elaboração identitária dos imigrantes austríacos, principalmente após o seu fim, ao término da Primeira Guerra Mundial, acontecimento que se enquadra no progressivo desaparecimento dos grandes impérios do passado (VAN DÜLMEN, 1990, p. 154). ${ }^{3}$ A menção ao "Império" consta nos textos de recuperação histórica desenvolvidos por alguns descendentes, mas arrefeceu seu papel de referencial diacrônico de identidade. E os toponímicos marcadores de memória mais recorrentes passaram a ser a Áustria e a região do Tirol. ${ }^{4}$ Como afirma Candau (2011, p. 94), precisamos estar atentos aos movimentos simbióticos da memória e da identidade: "Na escolha dos acontecimentos destacados, esse ordenamento das referências memoriais, é preciso observar o trabalho de construção da identidade que vai se fundar sobre os memoranda, quer dizer, as coisas 'dignas de entrar na memória”.

Para a compreensão da base histórica da identidade "austríaca” local, nos valemos dos textos produzidos em períodos de comemorações do aniversário da chegada dos primeiros imigrantes austríacos em ljuí, em 1893, como ocorreu em 1933 (40ํaniversário). Na efeméride, foi produzido um folheto de autoria de Ludwig Streicher, o Festschriftaus Anla $\beta$ der 40 jährigen Wiederkehr der Niederlassung der Österreicher-Kolonie in ljuhy (publicação comemorativa ao $40^{\circ}$ aniversário de um ramo da colônia austríaca em ljuhy), narrando a história de um grupo de imigrantes que chegou ao Rio Grande do Sul de forma organizada. Este opúsculo foi traduzido com adaptações mais de 50 anos depois (STREICHER; FRIEDRICH, 1988) e, a partir de sua leitura, ficamos sabendo que estes imigrantes, na Áustria, trabalhavam em uma fábrica de armamentos, na cidade de Steyer, que demitiu sete mil de seus dez mil empregados por falta de encomendas, num contexto de crise das indústrias metalúrgicas, o que, associado à busca de mão de obra europeia por parte do governo brasileiro, motivou a emigração para a América. Portanto, estes imigrantes participavam das migrações transoceânicas direcionadas pelas demandas (ou dispensas) diferenciadas de mão de obra do capitalismo ocidental (KLEIN, 2000, p. 25).

Por um relato colhido nos anos 1980 (WEBER, 1998, p. 37), sabemos que as mazelas econômicas também conduziram patrões à emigração. 0 avô de Rodolfo Wolf fora proprietário de uma fábrica de enfeites (vidro colorido, botões, etc.) na Áustria, e inclusive comerciava com o exterior, principalmente com a Rússia, mas a falta de pagamento pelas mercadorias vendidas a prazo levou-o à beira da falência, o que o fez vender a fábrica e optar pela emigração quando o pai de Rodolfo tinha 17 anos. Antes de se instalarem na área rural de ljuí, em torno de 1910, as três gerações da família residiram em Cachoeira, cidade de colonização mais antiga, onde o pai de Rodolfo, além de agricultor, trabalhava como guarda-livros, o que aponta a formação escolar prévia do filho do fabricante. Rodolfo,

\footnotetext{
${ }^{2}$ Sobre a noção de "realce" ver Poutignat e Streiff-Fenart (1998, p. 166).

${ }^{3}$ Jane Burbank e Frederick Cooper (2015) discordam do inevitável movimento de um mundo de impérios para um mundo de Estados-nações e recuperam características históricas dos impérios como, por exemplo, a diversidade interna.

${ }^{4}$ A procedência do Tirol indicaria grupos de fala italiana (PRUTSCH, 2011, p. 22), contudo, nomes de entidades, sobrenomes, casamentos com imigrantes alemães (parte dos quais é católica) indicam uma identificação germânica destes imigrantes.
} 
nascido no Brasil, trabalhou em uma fábrica de caramelos de propriedade de uma família de ascendência alemã, ocupando um posto de destaque, o de confeiteiro.

Pelo relato do autor do folheto de 1933, sabe-se que as 93 famílias originárias da cidade de Steyer obtiveram garantias de um diplomata brasileiro de que seriam assentadas no sul do Brasil; e 55 destas famílias, após chegarem a Porto Alegre, optaram por ljuí, onde se instalaram, em 1893 (Tabela 2), em áreas rurais contíguas, as chamadas "linhas": Linha 5, Linha, 6, Linha 7 e Linha 8, cuja sede era a Linha 6.

Quando narra as dificuldades dos primeiros tempos, Steyer expõe situações dramáticas, parte delas ampliada pela inexperiência de populações urbanas com um ambiente desconhecido e agreste: casas de bambu consumidas por cupins; produção de grãos atacada por roedores; venda de objetos pessoais trazidos da Europa para garantir a sobrevivência; salário recebido em moeda desvalorizada; privações alimentares; ônus da Revolução Federalista ${ }^{5}$ que se espalhava pelo estado; e perdas de produtos e vidas na travessia de rios. 0 narrador justifica a superação das condições difíceis dos primeiros tempos pelo "espírito comunitário, dedicação e perseverança”, garantia do "progresso" conquistado. 0 relato indica que a situação deu origem a uma forte "crença subjetiva na procedência comum”, decorrente de “lembranças de colonização e migração” (WEBER, 1994, p. 270), pois, desde a condição de operários metalúrgicos, o grupo permanecia compartilhando experiências, o que facilitou a emergência de um habitus que fomentava a coesão interna necessária à sobrevivência na nova terra. Pelo modo como se dirige tanto ao grupo como à sociedade envolvente, mostrando as virtudes daquele, Streicher pode ser considerado um intelectual étnico (WEBER, 2014). Como afirma Haiske (2017, p. 41), “o documento escrito por Ludwig enraizou a narrativa dos momentos iniciais da imigração desse grupo de emigrantes para o Brasil”.

Como vimos, outros imigrantes austríacos chegaram à Colônia ljuhy nos anos e décadas seguintes, o que denota a existência de correntes migratórias que se direcionam para uma localidade onde há conterrâneos previamente instalados.

No início da segunda década do século XX, chegaram a ljuí o jurista e jornalista Roberto Löwe e sua esposa Julia Löw. A trajetória de Roberto Löw ilustra as vicissitudes de um súdito do Império Austro-Húngaro. Em 1900 o casal deixou a Boêmia, onde antigos ódios entre alemães e tchecos haviam dado origem a uma "tchequisação", e emigrou para o Brasil, acabando por se instalar em ljuí em 1912 com seu jornal Die Serra-Post (FISCHER, 1972, p. 5, 13). Anos depois, Roberto Löw estava na Europa com o filho mais velho para uma exposição internacional de livros e artes gráficas, em 1914, quando estourou a Primeira Guerra Mundial. Ele deixou então o filho com suas irmãs em Viena e, na condição de alferes da reserva do exército austro-húngaro, apresentou-se ao comando militar, só retornando a ljuí em 1918 (FISCHER, 1972, p. 7, 15). Löw é um personagem que justifica um estudo

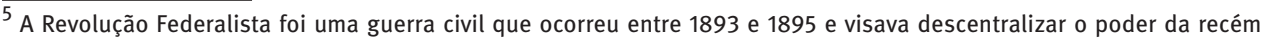
proclamada República. Com início no Rio Grande do Sul, o conflito atingiu também Santa Catarina e Paraná.
} 
no âmbito da história "transnacional", que se propõe a pensar a história da humanidade sem fronteiras, que "enfatiza as redes, os processos, as crenças e as instituições, transcendendo o espaço nacional” (PRADO, 2012, p. 19).

Roberto Löw defendia a "unidade étnica de todos os alemães" (FISCHER, 1972, p. 16), caracterizando-se como um dos líderes teuto-brasileiros do sul do país. ${ }^{6}$ Durante as duas conflagrações mundiais, que foram períodos de restrição ao uso de idiomas estrangeiros, na imprensa, nas associações e na linguagem cotidiana, a família Löw atuou, principalmente por meio do Correio Serrano, versão nacional do Die Serra-Post, como mediadora entre a população local de origem germânica e as autoridades políticas. Roberto faleceu em 1943, mas a ação familiar tem continuidade, tanto na cidade quanto entre seus conterrâneos austríacos.

Alguns imigrantes que ocuparam lotes rurais, principalmente das gerações mais jovens, em poucas décadas também estavam atuando no meio urbano. Franz Prauchner, que chegou com sua família em ljuí aos 13 anos de idade em 1893, a partir da emancipação do município, em 1912, passou a ocupar cargos de escrivão e agente bancário e, na década de 1930, foi reconhecido por sua vinculação ao Partido Republicano Castilhista (TIM; GONZALEZ, 1934). No Álbum ilustrado do Partido Republicano, de 1934, os nomes de Franz Prauchner e sua esposa Aloise Schäffl estão descritos como Francisco Prauchner e Luiza Schöffel Prauchner, certamente para produzir efeito de nacionalização.

Integrando-se ao ambiente interétnico, os austríacos, junto com outros descendentes de imigrantes europeus (alemães e holandeses), fundaram, em 1915, a Schutzenverein Tell, que no contexto da nacionalização (1938) passou a denominar-se Sociedade de Atiradores Tell (AUSTRÍACOS, 2013, p. 13). 0 fato de terem recebido armas quando foram demitidos na Áustria, certamente contribuiu para sua participação nesta entidade recreativa.

0 quadragésimo aniversário da chegada dos primeiros imigrantes foi festejado em março de 1933 na Linha 6, com a presença de 1.500 pessoas, entre as quais autoridades municipais e o cônsul austríaco. ${ }^{7} 0$ orador da cerimônia, em nome da comissão organizadora, foi o jornalista Ülrich Löw, filho de Roberto Löw. A família Löw, proprietária do jornal Correio Serrano e, a partir de 1928, da Litografia Serrana, importante empresa gráfica da região, não pertencia às levas pioneiras de austríacos do final do século XIX, como se viu anteriormente, mas identificou-se com eles, como ocorreu com descendentes de austríacos que migraram para ljuí vindos de colônias mais antigas (BINDÉ, 2007, p. 98). 0 Correio Serrano sempre abriu espaço para as efemérides dos diferentes imigrantes locais, porém, a vinculação à entidade austríaca tornava os Löw membros notáveis do grupo, aptos a exercerem o papel de intelectuais étnicos e, por meio do jornal, garantirem uma grande visibilidade a um grupo relativamente pequeno.

\footnotetext{
${ }^{6}$ Durante as duas guerras mundiais da primeira metade do século $\mathrm{XX}$, nas quais o país de origem dos imigrantes de fala alemã estava em oposição às frentes às quais o Brasil se aliou, os líderes teuto-brasileiros tiveram um importante papel de mediação social (SILVA, 2006, p. 180-216).

7 “Imigração Austríaca. A festa dos 40 anos”. Correio Serrano. ljuí. Encarte. 27 fev. 1988.
} 
Como contraponto, tomemos o caso dos imigrantes suecos, uma vez que dois terços das 150 famílias registradas na Tabela 1 se dirigiram a ljuí entre 1891 e 1892, um contingente semelhante ao dos austríacos. Os registros memoriais relativo aos "suecos" e sua visibilidade social, nestas décadas intermediárias do século XX, são bem mais escassos.

Na Figura 2 vemos mulheres de várias idades trajadas com vestes consideradas representativas da identidade austríaca. Tais símbolos, portados coletivamente em dias festivos, e as próprias festividades exercem influência sobre as gerações mais novas, as quais, mesmo não tendo a experiência ou memória da vida na Áustria, absorvem a memória coletiva:

Se colocarmos em primeiro plano os grupos e suas representações, se concebermos o pensamento individual como uma série de pontos de vista sucessivos sobre os pensamentos desses grupos, então compreenderemos que eles possam recuar no passado e ir mais ou menos longe conforme a extensão das perspectivas que lhe oferecem cada um desses pontos de vista sobre o passado tal como é representado nas consciências coletivas das quais participa (HALBWACHS, 1990, p. 129).

FIGURA 2

Grupo de senhoras com trajes típicos durante os festejos dos 40 anos da imigração austríaca na Linha 6 Leste (Ijuí/RS), 25/05/1933

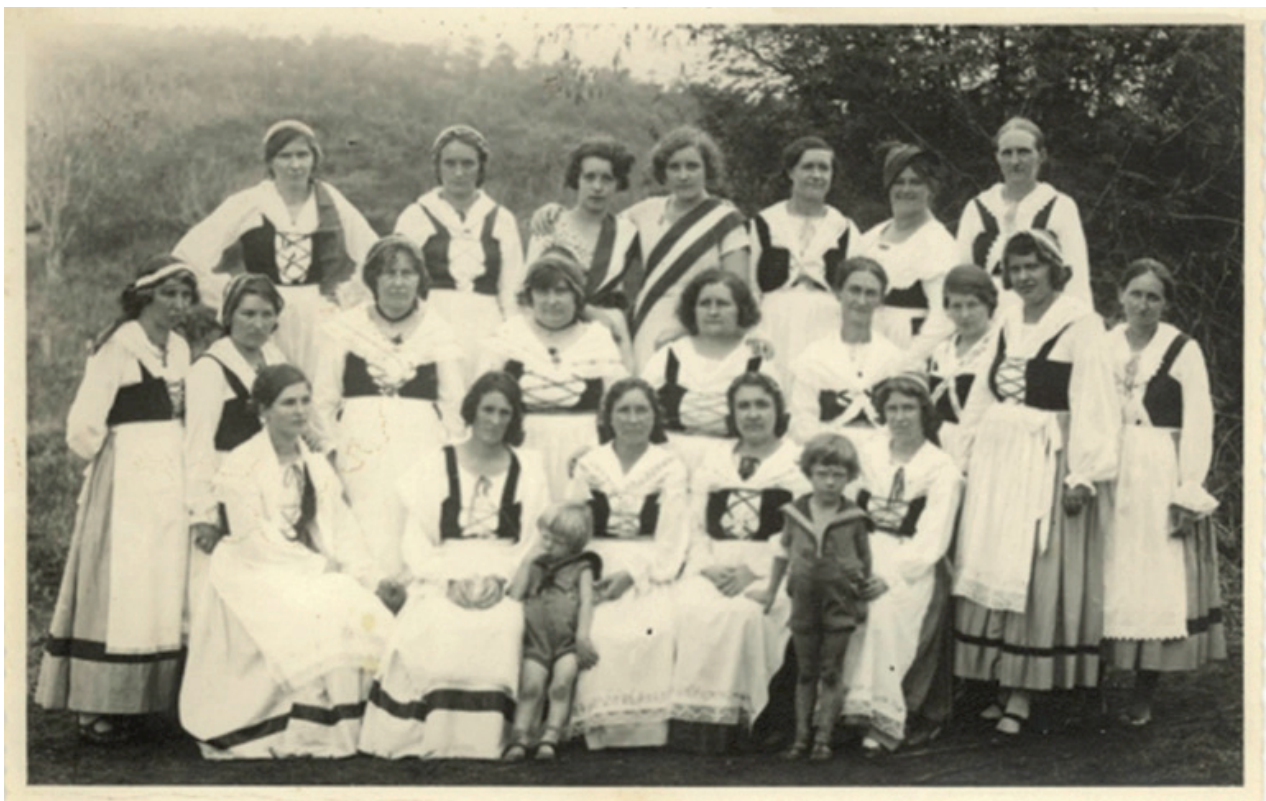

Fonte: Museu Antropológico Diretor Pestana. FIDENE. CB 4.4 0003.

Durante o Estado Novo, com o avanço do ensino público e a nacionalização dos nomes de entidades, a Allgemeiner Deutscher Schulverein (Sociedade Escolar Alemã, Figura 1), que funcionara ao mesmo tempo como escola e como sociedade recreativa, sofreu alterações por interferência externa: a escola foi incorporada pelo Estado e a sociedade mudou seu nome para 12 de Outubro, celebrando a data da sua fundação em 1898. 
Após 1933, em outras décadas, a data foi também comemorada, contribuindo para que a memória do grupo adquirisse permanência a partir das rememorações. ${ }^{8} \mathrm{Em} 1978$, foram comemorados, na Linha 6 Leste, os 80 anos da Sociedade Recreativa 12 de Outubro, com homenagem aos pioneiros de 1893 e entrega de títulos honoríficos aos apoiadores da comunidade austríaca. Estas sucessivas comemorações cristalizaram a chegada dos “pioneiros de 1893" como uma data emblemática, a qual resistiu à posterior divulgação de novos dados sobre a imigração austríaca para ljuí: antes de os "pioneiros de 1893", chegaram algumas famílias em 1892 (AUSTRÍACOS, 2013, p. 8). As informações dissonantes vieram à tona quando o Museu Antropológico Diretor Pestana de ljuí, principal acervo documental da cidade, estava justamente colaborando com a produção de textos e coleta de imagens sobre as "etnias" da cidade. A pesquisa histórica com frequência entra em desacordo com a memória.

Não houve recuo na data da comemoração, o que mostra o significado dos "acontecimentos fundadores" e, sobretudo, coletivos para a memória que lastra a história comum (POUTIGNAT; STREIFF-FENART, 1998, p. 165). De modo semelhante, a Linha 6 Leste permanece com a alcunha "rincão dos austríacos", mesmo com a migração de austríacos para a cidade e a transferência de terras para não austríacos, como descendentes de italianos e poloneses, alguns dos quais associados da Sociedade Esportiva e Recreativa 12 de Outubro.

FIGURA 3

Capela católica da Linha 6 Leste, em ljuí/RS, local ocupado por imigrantes austríacos no final do século XIX

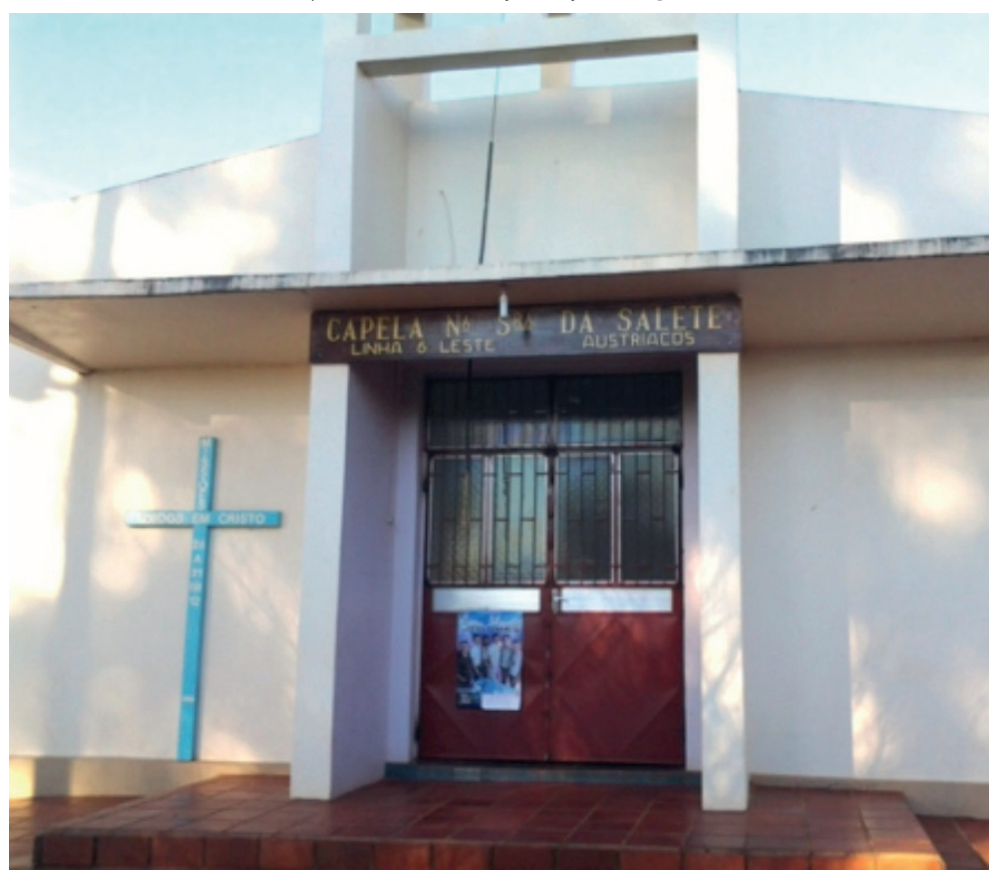

Imagem da autora, 27 jul. 2014.

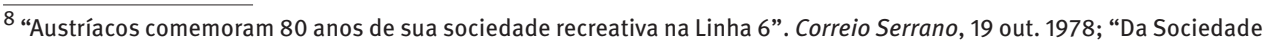
Escolar à Sociedade 12 de Outubro", Correio Serrano, Encarte, 27 fev. 1988.
} 
Retomando a ideia de "unidade étnica de todos os alemães" defendida por Roberto Löw segundo seu biógrafo, em nível local isto certamente ocorreu, seja pela proximidade entre imigrantes alemães e austríacos, seja pela homogeneização do olhar externo que identificava estes dois grupos pela língua e pelos sobrenomes, fatores que contribuíram para gerar uma identidade "englobante" de caráter positivado. Para postular que imigrantes austríacos encontraram um ambiente favorável ao desenvolvimento de sua identidade no interior do Rio Grande do Sul na primeira metade do século XX, façamos um contraponto com pesquisas nos anos 1970 nos Estados Unidos, que revelaram que etiquetas pejorativas foram "aplicadas indiferentemente a pessoas provenientes do conglomerado geopolítico austro-húngaro, sem preocupação com sua verossimilhança étnica ou geográfica” (POUTIGNAT; STREIFF-FENART, 1998, p. 145). Como lembram Prutsch, Bertonha e Szente-Varga (2017), emigrantes podem “desaparecer” da história e, consequentemente, da historiografia, se ocorrer uma equiparação das categorias língua, etnia e religião que não existia na origem. No caso em estudo, as aproximações entre alemães e austríacos não levaram ao desaparecimento das identidades específicas.

Foi no Clube “Alemão" que, em 1933, a colônia austríaca comemorou com um banquete os 40 anos da chegada das primeiras famílias; depois a comitiva dos festejos seguiu para a sede da Sociedade Austríaca (12 de Outubro), no interior do município. ${ }^{9}$ A identificação entre ambos os grupos falantes da língua alemã também era feita de modo externo. Por esta razão, austríacos também se preveniram de investigações da polícia local durante a Segunda Guerra Mundial, como foi o caso da família Pranzl, cujo retrato do kaiser Franz Joseph, o imperador que falecera em 1916, foi parar no forro da casa. Por uma reportagem, sabemos que um exemplar do emblemático retrato ainda fazia parte da ornamentação da longeva Sociedade 12 de Outubro em 1990. ${ }^{10}$

E os casamentos interétnicos ocorreram não apenas com a primeira geração nascida no Brasil, mas em gerações anteriores, como mostram habilitações de casamento do Juízo Distrital Villa de ljuhy da década de 1920, que se referem a três homens da mesma família. Pela habilitação de Ludovico Kettenhuber e Frida Michalski, de 1924, sabemos que os noivos nasceram em ljuí no ano de 1903, filhos de imigrantes, sendo os pais de Frida naturais da Rússia e agricultores, residentes no 1 ํㅡistrito do município, e os pais do moleiro Ludovico eram procedentes da Áustria. ${ }^{11} \mathrm{O}$ irmão mais velho de Ludovico, Leopoldo João Kettenhuber, que em 1926 estava com 29 anos, precisou levar testemunhas para compensar a ausência de certidão de nascimento, ocorrido na Áustria em 1896, para dar andamento a seu casamento com a jovem Anna Krupp, de 16 anos, cujos pais nasceram na Alemanha. No ano seguinte, 1927, Frederico Kettenhuber, que, ao contrário de seu irmão mais velho, era nascido no Brasil em 1900, apresentou-se ao juiz para casar-se com Mariah

\footnotetext{
9 Correio Serrano, n. 19, p. 1, 08 mar. 1933.

10 Zero Hora, Porto Alegre, p. 30, 23 jul. 1990.

11 O pai dos três rapazes, Leolpold Kettenhuber, é um dos “pioneiros” que chegou em 1893.
} 
Hölzle, cuja mãe era da Áustria e o pai da Alemanha. Estes casamentos não impediam que continuassem a existir sociedades e identidades “alemãs" e "austríacas".

\section{O passado como empreendimento: o lugar dos "austríacos" na cidade "diversificada"}

Em meados da década de 1980, às vésperas de completar o centenário de sua fundação, o município de ljuí buscava alternativas para enfrentar a crise que atingiu a economia regional, centralizada na produção da soja. Na mobilização dos sojicultores, que se espalhou em 150 municípios do estado do Rio Grande do Sul, máquinas foram concentradas nas ruas e estradas e manifestações ocorreram em praças públicas, cooperativas e sindicatos. ${ }^{12} \mathrm{Na}$ cidade, lideranças políticas e sociais reuniram-se num projeto que ficou denominado "A retomada do desenvolvimento". ${ }^{13}$ Uma das propostas que logrou efetivos resultados foi a criação da Festa Nacional das Culturas Diversificadas, a Fenadi.

A festividade, promovida pela União das Etnias de ljuí (Ueti), com sede na Associação Comercial, e realizada anualmente no parque de exposições municipal da cidade, tem um explícito viés econômico, pois movimenta o turismo a cada edição. ${ }^{14}$ Porém, seu maior significado cultural está na revitalização e no incentivo ao resgate de memórias dos antepassados. Na edição de 1992 (6- Fenadi), estavam presentes alemães, poloneses, italianos, austríacos, holandeses, portugueses, letos, árabes, afro-brasileiros, espanhóis, suecos, além dos "gaúchos", ${ }^{15}$ indicando que a cidade distanciava-se da antiga classificação de seus habitantes entre "brasileiros" e "de origem" (WEBER, 2002). Foi esta festividade, cuja primeira edição ocorreu em 1987, que deu maior visibilidade aos "austríacos” locais e a outros grupos menos conhecidos e, com esse incentivo, à diversidade, diluindo a narrativa cristalizada que destacava a imigração de alemães, italianos e poloneses. Na década de 1990, no contexto da promoção destas festividades étnicas na cidade, os suecos se movimentaram e festejaram o centenário da sua imigração (1891-1991).

A movimentação étnica não se restringe à festa realizada em outubro durante o aniversário do município. Ela ancora-se na existência de centros culturais étnicos que promovem outras atividades ao longo do ano e aos quais foi reservado um espaço no Parque de Exposições Wanderley A. Burmann para a construção de suas "casas típicas”. 0 Centro Cultural Austríaco de ljuí foi fundado em 1988 e, no ano seguinte, construiu sua casa no parque, como veremos adiante. Desenvolveu-se na cidade de ljuí uma precoce versão daquilo que viria a ser conhecido como história popular ou história pública, a qual, em suas manifestações mais recentes em outros países, reconhece a importância de museus e

\footnotetext{
12 Correio Serrano, p. 2, 15 jun. 1985.

13 Ver Jornal da Manhã, 24 jul. 1985, caderno especial.

14 Sobre a motivação turística no embrião da Fenadi, ver Jornal da Manhã, 24 jul. 1985, caderno especial, p. 9.

15 “Casa de cultura étnica”, in Associação Comercial de ljuí, [1992], p. 29.
} 
projetos patrimoniais para uma agenda política de formação contínua, diversidade, acesso e educação (DE GROOT, 2009, p. 236).

Esta valorização de ascendências étnicas múltiplas, corporificadas em uma festividade conjunta, foi produto da elaboração de intelectuais, mas não de "intelectuais étnicos", pois, neste caso, a ação foi protagonizada por acadêmicos dos quadros da instituição de ensino superior local, a Universidade Regional do Noroeste do Estado do Rio Grande do Sul (Unijuî). Em sintonia com discussões que, posteriormente, passaram a ser conhecidas como “multiculturais”, Mario Osório Marques, então editor universitário, deixou manifesta sua convicção teórica, inspiradora de sua prática, de que a convivência com a pluralidade é benéfica às sociedades, pois é "o caráter relacional da etnia que a torna significativa" (MARQUES, 1987, p. 8).

É preciso observar que a percepção da multiplicidade local já havia sido registrada anteriormente. A principal publicação, escrita originalmente em 1967, é a do biógrafo de Roberto Löw, Martin Fischer (1987), fundador e diretor do Museu Antropológico Diretor Pestana, vinculado à Unijuí. Outro texto, bem mais antigo, de 1898, é do pároco Antony Cuber (1975, p. 30), que descrevia a Colônia de ljuhy, fundada em 1890, como "Babel do novo mundo". As origens históricas do contexto interétnico local devem ser associadas à tentativa de combater os chamados "quistos étnicos" nos primeiros anos da República, e, dessa forma, nas colônias oficiais, evitava-se instalar imigrantes de uma única procedência. Aos imigrantes somavam-se, em maior ou menor número, luso-brasileiros, hispânicos, descendentes de africanos e de nativos.

No contexto da mobilização memorialística, decorrente do incentivo à afirmação da diversidade étnica do município, foi fundado, em novembro de 1987, logo após a realização da primeira Fenadi, o Centro Cultural Austríaco de ljuí. No ano seguinte, durante o transcurso dos festejos dos 95 anos da imigração austríaca, foi lançada, pelo cônsul austríaco de Porto Alegre, a pedra fundamental da Casa Típica Austríaca (Centro de Cultura Austríaca), em estilo tirolês, no parque de exposições municipal (AUSTRÍACOS, 2013, p. 1617). Foi neste momento que o texto de Streicher, que fazia parte desta "memória oficial", foi traduzido, com adaptações, e publicado no Correio Serrano, permitindo que gerações mais novas de descendentes de imigrantes, que não dominam o idioma alemão, tivessem acesso à memória dos antepassados (HAISKE, 2017, p. 52). 
Figura 4

Parque de Exposições Wanderley A. Burmann. Centro Cultural Austríaco, ljuí/RS

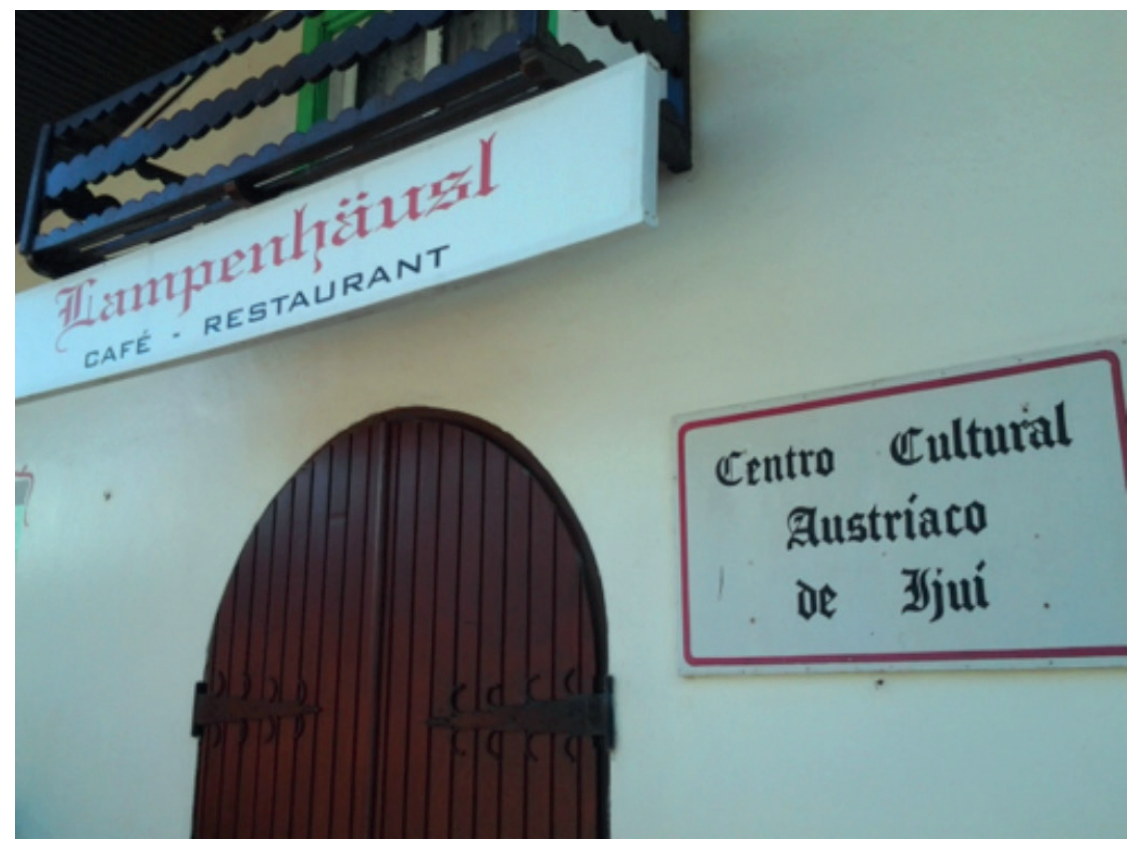

Imagem da autora, 28/07/2014.

Os registros memoriais foram reforçados pela criação, no Centro Cultural, de um minimuseu "com um acervo formado por livros, jornais, revistas, formulários, certificados, fotografias, panfletos, quadros, peças de artesanato, louças antigas, bordados, vestimentas, ferramentas, utensílios, móveis, entre outros" (AUSTRÍACOS, 2013, p, 16). Desde 1988 existem também dois grupos de dança, o "Lustige Tiroler" e o grupo infantil “Tanz Gruppe Sissi” (AUSTRÍACOS, 2013, p. 26), os quais, pela busca de informações nem sempre conhecidas pelos descendentes (partituras, coreografias, figurino), representam uma "invenção" de etnicidade que se ancora em um passado tão mítico quanto real. A recorrente referência à região do Tirol pode ser vista como a parte que representa o todo.

Estamos aqui diante de uma modalidade popular de fazer história (Popular Historymaking), na qual a cultura que se expressa pode ser tanto uma herança direta quanto uma recuperação de algo com o qual o indivíduo ou o grupo havia perdido contato (ROSENZWEIG; THELEN, 1998, p. 55). Quanto à problemática da “invenção”, retome-se Steve Fenton (2003, p. 14):

[...] a etnicidade se refere à construção social da descendência e da cultura, à mobilização social da descendência e da cultura e aos significados e implicações dos sistemas de classificação construídos à sua volta. Pessoas ou povos não possuem simplesmente culturas ou partilham de ancestralidade, eles elaboram-nas na ideia de uma comunidade fundada nesses atributos. 
A ideia de "Áustria” pode incorporar várias imagens, a começar pelo velho Império Austro-Húngaro. Da região da Boêmia (futuras Checoslováquia e República Checa), vieram, por exemplo, dois referenciais “austríacos”, Roberto Löw, visto anteriormente, e Lovina Preissler, casada com o austríaco Kühas. A avó e bisavó "Levina” legou aos netos e bisnetos, nascidos em casamentos interétnicos, a identificação "austríaca” (BINDÉ, p. 119, 124). Alguns imigrantes podiam descender de austríacos emigrados em séculos passados para outras áreas da Europa. ${ }^{16} \mathrm{~A}$ imagem da "Áustria”, assim, dá uma centralidade, continuidade e persistência ao que é descentrado (HALL, 1997, p. 25), descontínuo e mutável. Existem elementos culturais que dão consistência a esta vinculação com o passado, entre eles o cultivo da música, com destaque para o uso de violino, que, em uma mesma família, acompanhou várias gerações: entre os descendentes do patriarca Johann Prauchner, eram músicos e professores de violino um filho, também imigrante, e um neto, que por sua vez legou a tradição musical a seus filhos (BINDÉ, 2007, p. 67, 72).

Os agentes étnicos atuais têm um perfil diferente dos antigos, mesmo considerando-se que há descendentes dos pioneiros entre eles. 0 fato de descendentes de casamentos interétnicos sucessivos assumirem-se enquanto "austríacos", podendo escolher avós alemães e italianos, nos remete às teorias da "escolha" no campo dos estudos étnicos (POUTIGNAT; STREIFF-FENART, 1998, p. 100). Às vezes isso pode ter relação com o protagonismo de um ancestral, que lega a seus descendentes uma forte memória da terra de origem. Nesse impasse do historiador ante a complexidade das "origens", a noção de "atribuição" de Barth (2000), ou melhor, de autoatribuição, é a que melhor ampara a interpretação. Rosenzweig e Thelen (1998, p. 118) constataram que seus entrevistados que falaram sobre sua herança étnica eram cônjuges em casamento misto ou produtos dele e aprender esta história étnica era, para eles, uma maneira de tentar descobrir sua própria identidade, classificando peças de muitas tradições. A pesquisa que embasa o presente artigo contou com a colaboração do diretor do Departamento de História e Pesquisa do Centro Cultural Austríaco de ljuí, Eloi Nadir Samrsla, que partilhou muitos materiais. Sua esposa, mesmo sendo descendente de alemães, tem atuação expressiva no setor artístico do Centro Austríaco, contribuindo, portanto, com a história dos antepassados de seus filhos.

\section{Concluindo: a reivindicação da origem em diferentes tempos}

Na constante reelaboração das representações, o novo transforma o antigo. A entidade austríaca criada em 1987 é bem diferente da de 1898; na antiga havia maior número de pequenos proprietários rurais, nesta há vários empresários urbanos. Contudo, estes citadinos buscam elos com o passado e o Centro Cultural Austríaco realiza as comemorações importantes em parceria com a Sociedade 12 de Outubro localizada na Linha 6. 0 Centro

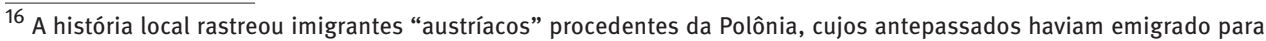
lá no século XVIII, quando Catarina II estimulou a vinda de imigrantes para a região de Lotz, então sob controle da Rússia (BINDÉ, 2007, p. 22).
} 
Cultural é atualmente o referencial contemporâneo, representando uma versão mais moderna e urbana, que tem na associação localizada na área rural sua fonte de legitimidade histórica. Estas referências históricas, a saga dos pioneiros de 1893, narrados por Streicher em 1933, a Allgemeiner Deutscher Schulverein convertida na Sociedade 12 de Outubro, conjugadas às realizações do Centro Cultural Austríaco, estão presentes na revista comemorativa dos 120 anos da imigração austríaca e dos 25 anos da fundação do Centro Cultural, editada em 2013. Estes investimentos culturais na unidade, nos antepassados e nas origens operam também como antídoto à mobilidade social e à diferenciação de classe, forças com poder de desgastar a experiência da origem e da história compartilhadas (FENTON, p. 161).

Em 2017 uma nova tradução da narrativa de Ludwig Streicher, Festschrift der Österreicher-Kolonie in ljuhy, procurou contornar os problemas da versão de 1988 , que ignorou, por exemplo, o número expressivo de adultos e crianças mortos e o abalo emocional decorrente (HAISKE, 2017, p. 48, 64). A tradução mais precisa foi elaborada no contexto de um estudo acadêmico realizado por um descendente de quinta geração de um dos imigrantes de 1893, ou seja, um novo agente a renovar e atualizar a memória e a história destes imigrantes austríacos a partir de outro lugar social de observação. Fatos tristes que Ludwig Streicher narrou para exaltar a coragem dos fundadores, e que Lothar Friedrich, seu tradutor em 1988, optou por deixar de lado em um contexto de revigoramento municipal, vieram à tona por meio do jovem universitário André Haiske, operando com o compromisso de historiador para fazer emergir aquilo que está submerso.

A existência de pessoas que reivindicam para si uma identificação "austríaca” perpassa mais de um século, porém, por mais que objetos, textos, discursos, trajes e festividades sejam retomados, os contextos se alteram, pois a situação social dos membros vai se transmutando e, por outro lado, a sociedade envolvente tem seu papel em cada época, em um momento cerceando manifestações divergentes com relação ao apregoado ideal nacional, em outro incentivando os grupos étnicos locais a expressarem suas especificidades, contribuindo para a aposta municipal na diversidade.

\section{Referências}

ANDERSON, P. Linhagens do Estado Absolutista. 3 ed. São Paulo: Brasiliense. 1995. ASSOCIAÇÃO COMERCIAL DE IJUÍ (ACI). Guia da cidade. ljuí, [1992].

AUSTRÍACOS. Revista Comemorativa aos 120 Anos da Imigração Austríaca - 1893/2013. 1988/2013 [ljuí, 2013, s.n.t.].

AZEVEDO, P. S. de S. de. Relações familiares e encontros étnicos em um povoado rural: solidariedades e conflitos em ljuí/RS (1890-1924). Dissertação (Mestrado) - Programa de Pós-Graduação em História, Universidade Federal do Rio Grande do Sul, Porto Alegre, 2018.

BARTH, F. Grupos étnicos e suas fronteiras [1969]. In: POUTIGNAT, P.; STREIFF-FENART, J. Teorias da etnicidade. São Paulo: Unesp, 1998. p. 187-227.

BINDÉ, A. C. As etnias em ljuí 6: os austríacos. ljuí: [s.n.], 2007. 
BOURDIEU, P. Espaço social e gênese de classe. In: BOURDIEU, P. 0 poder simbólico. Lisboa: Difel; Rio de Janeiro: Bertrand Brasil, 1989. p. 133-161.

BRASIL. Ministério da Agricultura, Indústria e Comércio, Diretoria Geral de Estatística. Recenseamento do Brazil. População, v. 4, 1a parte. Rio de Janeiro: Typ. da Estatística, 1926.

BURBANK, J.; COOPER, F. Um mundo de impérios. In: BOUCHERON, P.; DELALANDE, N. (org.). Por uma história-mundo. Belo Horizonte: Autêntica, 2015. p. 29-37.

CANDAU, J. Memória e identidade. São Paulo: Contexto, 2011.

CORREIO SERRANO, Ijuí, n. 19, 8 mar. 1933. [Reproduzido em Austríacos, 2013, p. 15].

CORREIO SERRANO, Ijuí, 19 out. 1978 [Reproduzido em Austríacos, 2013, p. 15].

CORREIO SERRANO, Ijuí, 15 jun. 1985.

CORREIO SERRANO, Ijuí, encarte, 27 fev. 1988. [Reproduzido em Austríacos, 2013, p. 11, 14].

CUBER, A. Nas margens do Uruguai. ljuí: Museu Antropológico Diretor Pestana, 1975 [1898].

DE GROOT, J. Consuming history: historians and heritage in contemporary popular culture. New York: Routledge, 2009.

FENTON, S. Etnicidade. Lisboa: Instituto Piaget, 2003.

FERREIRA, S. L. Nós não somos de origem: populares de ascendência açoriana e africana numa freguesia do sul do Brasil (1780-1960). Tese (Doutorado) - Programa de Pós-Graduação em História, Universidade Federal de Santa Catarina, Florianópolis, 2006.

FISCHER, M. A colonização de ljuí: um retrospecto histórico, sociológico e étnico. In: MUSEU ANTROPOLÓGICO DIRETOR PESTANA. Etnias diferençadas na formação de ljuí. ljuí: Livraria Unijuí Editora, 1987 [1967]. p. 21-43.

FISCHER, M. Dr. Roberto Löw, vida e perfil de um pioneiro do jornalismo serrano. Correio Serrano, ljuí, p. 3-19, 6 mar. 1972. (Edição comemorativa ao centenário de nascimento do Dr. Roberto Löw).

GANS, H. J. Symbolic ethnicity: the future of ethnic groups and cultures in America. In: SOLLORS, W. (ed.). Theories of ethnicity: a classical reader. New York: New York University Press, 1996. p. 424-459.

GÊNESIS, etnias no Rio Grande do Sul: registro dos imigrantes entrados no Estado do Rio Grande do Sul 1891-1892. Porto Alegre: EST, 1993.

HAISKE, A. Imigrantes austríacos no município de ljuí: relato da imigração por Ludwig Streicher. Trabalho de Conclusão de Graduação. Curso de Graduação em História, Universidade Federal de Santa Maria, 2017.

HALBWACHS, M. A memória coletiva. São Paulo: Vértice, Ed. Revista dos Tribunais, 1990.

HALL, S. Identidades culturais na pós-modernidade. Rio de Janeiro: DP\&A Editora, 1997.

INSTITUTO BRASILEIRO DE GEOGRAFIA E ESTATÍSTICA - IBGE. Recenseamento Geral do Brasil, Censo Demográfico. Rio Grande do Sul - 1940. Rio de Janeiro: Serviço Gráfico IBGE, 1950.

JORNAL DA MANHÃ, ljuí, caderno especial, 24 jul. 1985.

JUÍZO DISTRITAL VILLA DE IJUHY - Habilitação - Frederico Kettemhuber e Mariah Hölzle, 1927. (Arquivo Público do Estado do Rio Grande do Sul).

JUÍZO DISTRITAL VILLA DE IJUHY - Habilitação - Leopoldo João Kettemhuber e Ana Krupp, 1926. (Arquivo Público do Estado do Rio Grande do Sul). 
JUÍZO DISTRITAL VILLA DE IJUHY - Habilitação - Ludovico Kettemhuber e Frida Michalski, 1924. (Arquivo Público do Estado do Rio Grande do Sul).

KLEIN, H. S. Migração internacional na história das Américas. In: FAUSTO, B. (org.). Fazer a América: a imigração em massa para a América Latina. 2. ed. São Paulo: Edusp, 2000. p. 13-31.

LIMA JR., A.V. da C. "Prisão" em Lageado Pepino: gênese e efeitos sociais de uma ação exemplar. Tese (Doutorado) - Universidade Federal do Rio de Janeiro (UFRJ), Rio de Janeiro, 1996.

MARQUES, M. O. Introdução. In: MUSEU ANTROPOLÓGICO DIRETOR PESTANA. Etnias diferençadas na formação de ljuí. ljuí: Livraria Unijuí Editora, 1987. p. 7-9.

MUSEU ANTROPOLÓGICO DIRETOR PESTANA - MADP. Fotos digitais Fidene - Fundação de Integração, Desenvolvimento e Educação do Noroeste do Estado do Rio Grande do Sul. ljuí.

POUTIGNAT, P.; STREIFF-FENART, J. Teorias da etnicidade. São Paulo: Editora da Unesp, 1998.

PRADO, M. L. C. América Latina. Historia comparada, historias conectadas, historia transnacional. Anuario de la Escuela de Historia, Universidad Nacional de Rosario, n. 24, p. 9-22, 2012. Disponível em https://core.ac.uk/download/pdf/61701794.pdf. Acesso em: 12 abr. 2020.

PRUTSCH, U.; BERTONHA, J. F.; SZENTE-VARGA, M. (org.). Aventureros, utopistas, emigrantes: dellmperio Habsburgo a las Américas. [e-book]. Berlin: AHILA, Iberoamericana, Vervuert, 2017.

PRUTSCH, U. A emigração dos austríacos para o Brasil (1876-1938). Brasília: Embaixada da Áustria no Brasil, 2011. Mimeo.

ROSENZWEIG, R.; THELEN, D. The presence of the past. Popular uses of History in American life. New York: Columbia University Press, 1998.

SARNA, J. D. From immigrants to ethnics: toward a new theory of "ethnicization". Ethnicity, v. 5, p. 370-378, 1978. Disponivel em: http://www.bjpa.org/Publications/details. cfm?PublicationID=12079. Acesso em: 12 abr. 2020.

SILVA, H. R. K. da. Entre o amor ao Brasil e ao modo de ser alemão: a história de uma liderança étnica (1868-1950). São Leopoldo: Oikos, 2006.

SEYFERTH, G. A representação do “trabalho alemão" na ideologia étnica teuto-brasileira. Boletim do Museu Nacional, Rio de Janeiro, n. 37, 20 out. 1982.

STREICHER, L.; FRIEDRICH, L. Histórico depoimento - imigração austríaca. ljuí, 1988. Mimeo. Adaptação e tradução, por Lothar Friedrich, do original "24 Februar 1893 - 5 Marz 1933. Festschriftaus Anla $\beta$ der 40 jährigen Wiederkehr der Niederlassung der Österreicher-Kolonie in ljuhy", de L. Streicher.

TIM, O. B.; GONZALEZ, E. (org.). Álbum ilustrado do Partido Republicano Castilhista III. Porto Alegre: Livraria Selbach, 1934. (Reproduzido em ÁVILA, L. C. História de ljuhy de antigamente, 2018, DVD).

VAN DÜLMEN, R. Los inicios de la Europa moderna. 1550-1648. 4. ed. Madrid: Siglo XXI, 1990.

WACHOWICZ, R. C. 0 camponês polonês no Brasil. Curitiba: Fundação Cultural, Casa Romário Martins, 1981.

WEBER, M. Economia e sociedade. 3 ed. v. 1. Brasília: Editora da UnB, 1994.

WEBER, R. 0 trabalhador fabril em gestação: depoimentos sobre os anos 30 e 40 no interior do Rio Grande do Sul. ljuí: Unijuí, 1998. 
WEBER, R. A construção da "origem”: os “alemães" e a classificação trinária. In: RECKZIEGEL, A. L. S.; FÉLIX, L. O. RS: 200 anos definindo espaços na história nacional. Passo Fundo-RS: Editora da UPF, 2002. p. 207-215.

WEBER, R. Líderes, intelectuais e agentes étnicos: significados e interpretações. Diálogos, Maringá, v. 18, n. 2, p. 703-733, maio-ago./2014.

ZERO HORA, Porto Alegre, 23 jul. 1990.

\section{Sobre a autora}

Regina Weber é doutora em antropologia pelo Museu Nacional, Universidade Federal do Rio de Janeiro (UFRJ) e mestre e graduada em história pela Universidade Estadual de Campinas (Unicamp). Professora titular da Universidade Federal do Rio Grande do Sul, integrante do Departamento e do Programa de Pós-graduação em História.

\section{Endereço para correspondência}

Programa de Pós-Graduação em História/UFRGS

Av. Bento Gonçalves, 9500, prédio 43322 (IFCH), sala 205, Bairro Agronomia

91509-900 - Porto Alegre-RS, Brasil

\section{Abstract}

From Empire to multiethnic city: Austrians in the South of Brazil

This article focuses the circumstances which shaped the creation of a specific identity forimmigrants recognized as 'Austrians' in the South of Brazil. The main locus of this research is a small settlement in Rio Grande do Sul's inland, as we collected data from the end of the nineteenth century to the end of the twentiethcentury, comprising the finalyears of the AustroHungarian Empire, and locally witnessing late investment in ethnic memorialism. We highlight the agents who accomplish connections between distinct worlds and times, as well as the ways in which past representations are put into action.

Keywords: Austrian immigration. Austro-Hungarian Empire. Multiethnic. Memory. Representations. 


\section{Resumen}

Del imperio a la ciudad multiétnica: austríacos en el sur de Brasil

Este artículo se centra en las circunstancias que dieron forma a una identidad específica para los inmigrantes identificados como austríacos. El lugar principal de la investigación es un asentamiento en el interior de Río Grande del Sur y fueron recolectados datos que van desde finales del siglo XIX hasta finales del siglo XX, un período que contempla, en términos internacionales, la existencia, aunque unas pocas décadas a partir de su fin, del Imperio austrohúngaro y, en lo local, las recientes inversiones en el memorialismo étnico. Se hace hincapié en los agentes que conectan diferentes mundos y tiempos y en las formas en las que las representaciones del pasado se hacen operativas.

Palabras clave: Inmigración austríaca. Imperio Austrohúngaro. Multiétnico. Memoria. Representaciones.

Recebido para publicação em 14/04/2020

Aceito para publicação em 07/05/2021 